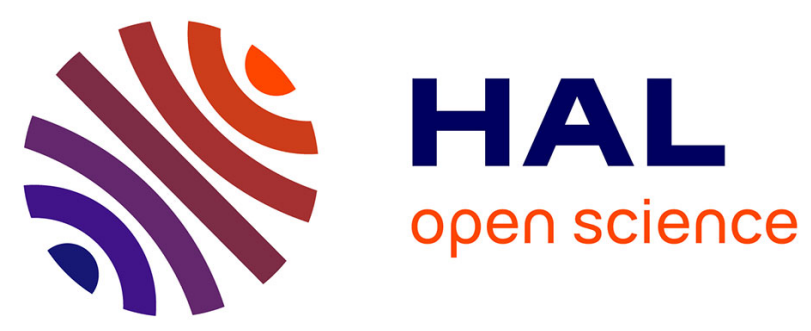

\title{
In situ neutron diffraction analysis of the influence of geometric confinement on crystalline swelling of montmorillonite
}

Karine Devineau, Isabelle Bihannic, Laurent Michot, Frédéric Villiéras, Farimah Masrouri, Olivier Cuisinier, Giovanna Fragneto, Nicolas Michau

\section{To cite this version:}

Karine Devineau, Isabelle Bihannic, Laurent Michot, Frédéric Villiéras, Farimah Masrouri, et al.. In situ neutron diffraction analysis of the influence of geometric confinement on crystalline swelling of montmorillonite. Applied Clay Science, 2006, 31, pp.76-84. 10.1016/j.clay.2005.08.006 . hal00089889

\section{HAL Id: hal-00089889 \\ https://hal.science/hal-00089889}

Submitted on 24 Aug 2006

HAL is a multi-disciplinary open access archive for the deposit and dissemination of scientific research documents, whether they are published or not. The documents may come from teaching and research institutions in France or abroad, or from public or private research centers.
L'archive ouverte pluridisciplinaire HAL, est destinée au dépôt et à la diffusion de documents scientifiques de niveau recherche, publiés ou non, émanant des établissements d'enseignement et de recherche français ou étrangers, des laboratoires publics ou privés. 


\section{In situ neutron diffraction analysis of the influence of geometric confinement on crystalline swelling of montmorillonite}

Karine Devineau ${ }^{1}$, Isabelle Bihannic ${ }^{1}$, Laurent Michot $^{1}$, Frédéric Villiéras ${ }^{1}$, Farimah Masrouri $^{2}$, Olivier Cuisinier ${ }^{2 *}$, Giovanna Fragneto $^{3}$, Nicolas Michau $^{4}$

1. LEM, Laboratoire Environnement et Minéralurgie, UMR7569 CNRS\&INPL, Ecole Nationale Supérieure de Géologie, BP 40, 54501 Vandoeuvre-lès-Nancy, France

2. LAEGO, Laboratoire Environnement, Géomécanique et Ouvrages, EA1145 INPL, Ecole Nationale Supérieure de Géologie, BP 40, 54501 Vandoeuvre-lès-Nancy, France

3. Institut Laue-Langevin, B.P.156, 38042 Grenoble Cedex 9, France

4. Andra, 1/7 rue Jean Monnet, Parc de la Croix Blanche, 92298 Chatenay-Malabry Cedex, France

Corresponding Author

F. Villiéras

Frederic.Villieras@ensg.inpl-nancy.fr

Fax: +33 383596255

Tel: +33 383596289

* Present address: LCPC, Laboratoire Central des Ponts et Chaussées, BP 4129, F-44341 Bouguenais 


\section{Abstract}

The swelling properties of a bentonite MX-80 and a Na montmorillonite obtained from MX80 purification were analyzed as a function of relative humidity in free and constrained conditions. Gravimetric and XRD techniques were used to study the hydration of powder and compacted pellets in non confined conditions whereas hydration under constrained conditions was investigated in situ by neutron diffraction using a cell specifically designed for the present study. MX-80 bentonite and purified montmorillonite were compacted to an apparent density of 1.7 and equilibrated at various relative humidities using $\mathrm{P}_{2} \mathrm{O}_{5}$ and solutions saturated with different salts allowing to work in a wide range of relative humidity between 0 and 0.98 .

At low relative humidity, the hydration of montmorillonite is similar in free and constrained conditions. For relative pressures higher than 50\%, swelling in constrained pellets deviates from that observed for free pellets. Reorientation phenomena of clay layers were also observed for bentonite and montmorillonite starting at 65\%RH. At 98\% RH, two well-defined basal spacings were obtained in the case of confined bentonite. The major peak corresponds to three-layer hydrates $(18.6 \AA)$ and the second one to two-layer hydrates (16 $\AA$ ). In contrast, only the latter peak is observed when hydration is realized in free geometrical conditions. In the case of Na montmorillonite, for the same relative humidity, the confinement cell did not resist swelling pressure. This was explained by the fact that, for the 1.7 density, porosity was too small to allow the formation of the three layer hydrates to compensate for water swelling pressure.

Keywords: bentonite, montmorillonite, XRD, neutron diffraction, hydration, confinement. 


\section{Introduction}

Bentonites are being used increasingly as sealing materials in the design of disposal facilities for hazardous waste. Placed as engineered barriers, they are required to inhibit the migration of contaminants from the waste to the surrounding environment. In particular, bentonites are frequently recommended as backfill materials associated with construction of high-level nuclear waste repositories (Madsen, 1998, Landais 2004). In the French context, bentonites are currently considered as choice materials for barrier design by Andra (French Agency for management of radioactive waste).

The sealing properties of bentonites are mainly due to their high content in swelling clay minerals (Choi \& Oscarson, 1996; Madsen, 1998; Push et al., 1990, 1999, 2003). In these materials, swelling is mainly controlled by the hydration of interlayer cations that compensate the structural negative charge of the clay layers. With increasing water contents, interlayer between clay platelets increases due to water adsorption around cations (Ben Rhaïem, 1987; Bérend et al, 1995; Bihannic, 1998; Bihannic et al., 2001; Cases et al ; 1992, 1997; Ferrage et al., 2005, Ormerod and Newman, 1993; Michot et al., 2005; Mooney et al., 1952; Newman, 1987; Norrish and Quirk., 1954; Sposito and Prost, 1982; van Olphen, 1977). The structural changes are associated with modifications of the porosity in and between clay aggregates both in volume and shape as shown by SAXS and USAXS experiments (Bihannic, 1998; Bihannic et al., 2001; Morvan et al., 1994). At moderate relative humidity, microscopic swelling of the clay occurs without any macroscopic modifications. When high relative humidities are reached, macroscopic swelling occurs due to osmotic equilibration between interlayer composition and bulk water condensed into the porosity (Komine \& Ogata, 1994, Norrish \& Quirk, 1954; Pusch and Yong, 2004; van Olphen, 1977).

Such a picture is valid for samples hydrated in free spaces. Much less is known in the case of compacted and confined materials. In that latter case, as macroscopic swelling can not take place, a swelling pressure appears in the material. Mechanical information related to swelling 
pressure is available (Komine \& Ogata, 1994; Low, 1980; Madsen, 1998; Stucki et al, 1984) but in situ analysis of microscopic swelling and water distribution between interlamellar space and porosity, is rare (Nakaoka et al, 2004). Simple calculations suggest that when the apparent density reaches a value of around 1.6, and for a water relative pressure of 0.98 , inter aggregate pores are no longer available and water molecules should only occupy interlayer spaces (Komine \& Ogata, 1994; Madsen et al., 1998; Sauzeat et al., 2001). These calculations need experimental validation regarding the structure and dynamics of water molecules in confined conditions. Such information could then provide new insights to predict the long-term transfer of contaminants through engineered clay barriers.

Neutron scattering techniques are well adapted to study samples under versatile experimental conditions, in particular under high pressure as sample holders transparent to neutrons can be built with high mechanical resistance. Such an advantage was already used for studying the status of water in clays under high-pressure and temperature conditions similar to those encountered in oil reservoirs (Skipper et al., 2000). The aim of this work is then to investigate by gravimetric adsorption, $\mathrm{XRD}$ and neutron diffraction the crystalline swelling in compacted montmorillonite samples equilibrated with increasing water vapor pressure in free space or in confined conditions at constant macroscopic volume.

\section{Material:}

A Na/Ca-bentonite (MX-80 from Wyoming) was used for this study. Detailed characterization of the bentonite has been performed by Sauzéat et al. (2001). The bentonite contains montmorillonite (80\%), quartz (3\%), K-feldspars (2\%), plagioclases $(9 \%)$, carbonates $(2 \%)$, mica (3\%) and other minerals (1\%). The bulk sample is composed by $86.1 \%$ of particles in a size-range less than $2 \mu \mathrm{m}, 8.8 \%$ of those in a size range of $2-50 \mu \mathrm{m}$, and $5.1 \%$ of those in a size-range higher than $50 \mu \mathrm{m}$. The purified and exchanged $\mathrm{Na}$ montmorillonite 
was obtained by sedimentation of coarse particles, carbonate dissolution at $\mathrm{pH} 5,80^{\circ} \mathrm{C}$ (sodium acetate - acetic acid buffer), 3 exchanges in $\mathrm{NaCl} 1 \mathrm{M}$ followed by several washing and centrifugation cycles to remove excess ions.

Structural formula of purified montmorillonite, determined by electron microprobe and energy dispersive X-ray attachment to transmission electron microscope, can be written as :

$\left(\mathrm{Si}_{3.98} \mathrm{Al}_{0.02}\right)\left(\mathrm{Al}_{1.55} \mathrm{Fe}^{3+}{ }_{0.09} \mathrm{Fe}^{2+}{ }_{0.08} \mathrm{Mg}_{0.28}\right) \mathrm{O}_{10}(\mathrm{OH})_{2} \mathrm{Na}_{0.18} \mathrm{Ca}_{0.10}$

Measured cation exchanged capacity of the purified sample is $97 \mathrm{meq} / 100 \mathrm{~g}$, as expressed on basis of air-dried sample. Though slightly different, these results generally concur with those published by Madsen (1998).

\section{Methods}

Gravimetric adsorption of water vapor on powders

Water vapor adsorption measurements were carried out on powders in a continuous gravimetric apparatus built around a Setaram MTB 10-8 symmetric balance (Poirier et al., 1987). Prior to each experiment, about $100 \mathrm{mg}$ of sample was outgassed overnight under vacuum $(1-2 \mathrm{~Pa})$ at the temperature of $120^{\circ} \mathrm{C}$. Water vapor was supplied from a source kept at $41{ }^{\circ} \mathrm{C}$, through a Grandville-Philips leak valve, at a slow flow rate to ensure quasi-equilibrium conditions at all times. The adsorption isotherms, mass adsorbed at $30^{\circ} \mathrm{C}$ versus quasiequilibrium pressure, were directly recorded on an X-Y recorder. Pressures were measured using a Texas fused silica Bourdon tube automatic gauge.

The monolayer capacity was determined from the adsorption isotherm by applying the BET equation (Brunauer et al., 1938). Specific surface areas were then estimated from monolayer capacities by taking into account a cross sectional area of $14.8 \AA^{2}$ for adsorbed water molecules as initially proposed by Harkins and Jura (Harkins and Jura, 1944). 
Water vapor adsorption measurements on free pellet were carried out at room temperature in a discontinuous gravimetric apparatus (Sigma70, KSV). Prior to analysis, the bentonite was pressed to obtain a disk with a dry density of 1.7 (dry sample mass $3.507 \mathrm{~g}, \mathrm{~d}=1.69 \pm 0.02$ ). Prior to experiment, the pellet was dehydrated at $200^{\circ} \mathrm{C}$ during two weeks. Water vapor relative pressure was then controlled by bubbling dehydrated air in water at controlled temperature during 12 hours for different relative humidities ranging from 40 to $98 \%$. Sample temperature was $28^{\circ} \mathrm{C} \pm 2^{\circ} \mathrm{C}$. Sample mass $( \pm 1.5 \mathrm{mg})$, temperature $\left( \pm 0.1^{\circ} \mathrm{C}\right)$ and relative humidity $( \pm 0.5 \%)$ were then continuously recorded in order to follow sample hydration. Variations in size (pellet thickness) were recorded during the course of adsorption using a cathetometer (accuracy $20 \mu \mathrm{m})$.

\section{Water vapor adsorption coupled to XRD analysis}

The evolution of X-ray diffraction patterns with water relative pressure was followed using a home made experimental set-up (Bérend et al., 1995). Bentonite was mixed with kaolinite used as an internal non-swelling reference, pressed into a pellet and placed inside a chamber allowing the control of relative humidity and temperature. The chamber kept at $30{ }^{\circ} \mathrm{C}$ was connected to a water vapor source. The water relative pressure in the chamber was controlled by changing the temperature of the water source. An Edwards pressure gauge (0-1000 mbars) was placed on the chamber for direct pressure measurements. This double measurement allows an accuracy of \pm 0.01 on relative pressure data. X-ray diffraction patterns were recorded simultaneously over $30^{\circ}(\theta)$ on an Inel CPS 120 curved detector using reflection geometry with CoK $\alpha$ radiation. Due to this geometry, the accuracy on d001 values is not perfect especially at low angles and can be estimated at $\pm 0.1 \AA$. The sample was outgassed before experiment at $30{ }^{\circ} \mathrm{C}$ under a residual pressure of $2 \mathrm{~Pa}$ during 24 hours. For each hydration state, equilibrium was checked by recording the evolution of X-ray diffraction 
patterns with time. The time for equilibrium was variable between 4 and 8 hours depending on the hydration pressure.

\section{Water vapor adsorption at constant volume coupled to neutron scattering analysis}

Special cells were designed to keep samples constrained at constant volume while allowing in situ hydration. They consist of two 2-mm thick and 30-mm wide sapphire windows placed on both sides of previously compacted clay pellets. The water vapor exchange takes place trough a porous ring (4-mm height and $3.2 \mathrm{~mm}$ thick) placed around the pellets (Figure 1).

Prior to compaction, the bentonite or purified montmorillonite was air-dried at $105^{\circ} \mathrm{C}$ during 48 hours. Dry powder was then introduced in a glove box flushed with dry nitrogen and containing $\mathrm{P}_{2} \mathrm{O}_{5}$ powder in order to limit relative humidity between 2 and $5 \%$. Dry pellets were compacted inside the porous ring at a density of $1.7( \pm 0.02)$. Cells were then mounted in the glove box. After compaction, bentonite pellets were equilibrated during 3 months at 65 , 81 and $98 \%$ relative humidities using $\mathrm{H}_{2} \mathrm{O}$ solutions saturated with $\mathrm{NH}_{4} \mathrm{NO}_{3},\left(\mathrm{NH}_{4}\right)_{2} \mathrm{SO}_{4}$ and $\mathrm{CuSO}_{4} .5 \mathrm{H}_{2} \mathrm{O}$, respectively. A dry sample was kept in a sealed container with $\mathrm{P}_{2} \mathrm{O}_{5}$ powder. In the case of montmorillonite pellets, two additional cells were equilibrated with solutions saturated with $\mathrm{K}\left(\mathrm{C}_{2} \mathrm{H}_{3} \mathrm{CO}_{2}\right)$ and $\mathrm{K}_{2} \mathrm{CO}_{3}$ at 23 and $44 \%$ relative humidity, respectively.

Neutron scattering experiments were carried out at Institut Laue Langevin (Grenoble, France) on beamline D16 using a wavelength of $4.54 \AA$. Data were recorded at wide angles both in transmission and reflection to avoid difficulties due to the presumed high orientation of particles inside compacted pellets. The scans were carried out in $\theta / 2 \theta$ conditions with a scan step of $1^{\circ} \theta$ and an acquisition time of $100 \mathrm{~s}$ per point. The diffracted neutrons were recorded on a bidimensional detector. The 2D image was converted in a radial distribution function $\mathrm{I}(\mathrm{q})$, were $\mathrm{q}$ is the scattering vector $(\mathrm{q}=4 \pi \sin (\theta) / \lambda)$. After transmission correction, the signal of the empty cell was subtracted from the regrouped data. The incoherent signal of water was 
estimated from scattering angular domain where clays do not exhibit any diffraction peaks (q values around 1) and this value was then subtracted from the whole data.

The cells used to keep samples constrained were designed both to collect data on the widest angular domain and to bear the swelling pressures developed in saturated samples. For the most hydrated ones, the signal was partially absorbed at large q values by the additional screws needed to support the largest pressures. A decrease in the intensity can then be observed on some samples for q values above $1.5 \AA^{-1}$.

Mosaicity was also evaluated by measuring the integrated intensity of two peaks (001 and (02-,11-) as a function of sample orientation relatively to the beam direction.

\section{Results and Discussion.}

Figure 2 presents the water adsorption isotherm obtained at $303 \mathrm{~K}$ on dry powders of raw MX-80 bentonite and of purified montmorillonite. The two isotherms display a similar shape, typical of swelling materials, the curve corresponding to montmorillonite being shifted towards higher adsorbed amounts due to the higher content in swelling compounds. The adsorbed quantity increases moderately for relative pressures $\leq 0.40$ and displays an important increase at higher relative pressure. Such a feature is typical of Na-exchanged montmorillonites (Cases et al ; 1992 ; Bérend et al, 1995). Even if the concept of a water surface area is debatable for swelling materials, the application of the BET equation to these isotherms yields values around 70 and $85 \mathrm{~m}^{2} \cdot \mathrm{g}^{-1}$, for bentonite and montmorillonite, respectively. In terms of adsorbed amount, the pelletized bentonite sample (dots in Figure 2) behaves as the powder. However, for a relative pressure around 0.80 , the thickness of the pellet increases by $4 \%$ upon water adsorption. The increase in thickness reaches $10 \%$ for a relative pressure of 0.98 .

The XRD evolution of basal spacing with water pressure is presented in Figure 3 for an MX80 pellet hydrated in free space. The pattern observed follows roughly the water adsorption 
isotherms with strong increases in d-spacing corresponding to the slope changes observed on the water adsorption isotherms. Under vacuum, the interlayer distance is close to $9.6 \AA$ as typically observed for Na-montmorillonites (Norrish \& Quirq, 1954; Mooney et al., 1952, Cases et al, 1992; Bérend et al., 1995, Ferrage et al, 2005). For a relative pressure between 0.36 and 0.41 , the $\mathrm{d}$-spacing increases significantly to reach a value around $11.6 \AA$. A pseudoplateau region, is then observed where the d-spacings increase slowly from 11.6 to $12.6 \AA$ for relative pressures between 0.41 and 0.61 . A second significant increase in basal distance is then observed for relative pressures around 0.65 where the $d$-spacing reaches a value around $14 \AA$. This value increases regularly with increasing water pressure and an interlayer distance of $16 \AA$ is reached for a relative pressure of 0.97 . It must be pointed out that, as revealed in various studies (Bérend et al. 1995; Christidis \& Eberl, 2003; Ferrage et al., 2005), the values thus obtained do not correspond to homogeneous hydration states but to complex interstratified structures with the coexistence of various n-layer hydrates. The evolution of dspacing observed in our study is very close to those observed on pure Na-montmorillonites (Bérend et al., 1995; Ferrage et al., 2005), which suggests that the compression of the sample does not affect the way in which interlayer cations hydrate in free volume condition. In addition, though chemical analyses reveal the presence of both sodium and calcium in the interlayer, the swelling behavior of bentonite is dominated by sodium ions.

Figure 4 presents the neutron diffraction patterns obtained in transmission on confined MX-80 bentonite (Figure 4A) and confined purified montmorillonite extracted from this bentonite (Figure 4B) equilibrated under various $\mathrm{H}_{2} \mathrm{O}$ relative pressures. Clearly visible 001 reflections, whose positions evolve with water relative pressure are observed. The peaks are broad in all cases. In the case of smectite, a diffraction pattern corresponding to a water relative pressure of 0.23 was recorded but is not shown here for clarity reasons, as it is nearly superimposed on the pattern obtained on the dry sample. In the case of bentonite for a relative pressure of 0.98 , the diffraction pattern exhibits a main peak at $18.2 \AA$ with a shoulder around $15.7 \AA$, which 
suggests that in this case, a three-layer hydrate is reached. In the case of smectite, for the same water relative pressure, no diffraction patterns were recorded as the sapphire window broke after roughly one month of hydration. This point will be discussed further in the following sections. In addition to 001 reflections, one can systematically observe a peak located at q $=1.41 \AA^{-1}(\mathrm{~d}=4.45 \AA)$ which is insensitive to water content. It corresponds to the $(02-, 11-)$ reflection and displays a higher intensity on smectite compared to bentonite. A peak that can be assigned to quartz at $\mathrm{q}=1.88 \AA^{-1}$ is clearly visible on bentonite (Figure $4 \mathrm{~A}$ ) and is also observed for smectite, revealing the presence in the initial samples, of quartz particles with sizes lower than $2 \mu \mathrm{m}$.

In all cases, the fact that 001 reflections are observed in transmission shows that the samples are not perfectly oriented, even after compaction. The strong differences observed between smectite and bentonite, in terms of relative intensities of 001 lines and hkl lines additionally suggest that the purified sample presents a better orientation than the raw bentonite material. In order to better assess the orientation properties, mosaicity experiments were carried out for all samples. Such experiments were performed on both the 001 and (02-,11-) lines. As the results obtained in both cases are nearly equivalent, only results relative to the 001 line will be presented here. Figure 5 presents the evolution of $\mathrm{I}(\alpha) / \mathrm{I}_{\mathrm{sym}}$ as a function of the incident angle for bentonite (Figure 5A) and montmorillonite (Figure 5B). $\mathrm{I}(\alpha)$ is the integrated intensity of the 001 line for a given incident angle $\alpha(\alpha=90$ when incident beam is perpendicular to sample surface) whereas $I_{\text {sym }}$ is the integrated intensity of the 001 line obtained in transmission in a $\theta / 2 \theta$ symmetrical geometry. Strong differences are observed between the two situations, as the curves corresponding to bentonite only display marginal changes whereas those corresponding to montmorillonite exhibit a strong angular dependence with a roughly symmetrical shape centered around $10^{\circ}$. In comparison with the other curves, the curve related to montmorillonite equilibrated at a relative water pressure of 0.65 is noisier 
than the other ones, which is due to the very weak broad 001 signal obtained in that case (Figure 4). In order to take into account the geometrical effects and sample absorption associated with our experiments, relative intensities can be corrected as follows:

$\mathrm{I}^{\prime}(\alpha)=\mathrm{A} . \mathrm{I}(\alpha) \quad$ and $\quad \mathrm{I}_{\mathrm{sym}}^{\prime}=\mathrm{A}_{\mathrm{sym}} \cdot \mathrm{I}_{\mathrm{sym}}$

where A and Asym represent absorption correction factors depending on incident and diffraction angles for a given angle a and in symmetrical geometry, respectively (Drits \& Tchoubar, 1990). For a given orientation $\omega(\omega=90-\theta-\alpha)$, with $\omega=0$ when the particles are parallel to the sample surface, the density of particles $p(\omega)$ is proportional to $I^{\prime}(\alpha) / I_{\text {symm }}^{\prime}$. Orientation function is then obtained from the integration and normalization to 1 of the density function between 0 and $90^{\circ}$. From instrumental constraints, orientation information was obtained only between 0 and $50^{\circ}$ and density functions were normalized from orientation function normalized to 0 at $50^{\circ}$. Histograms of Figure 6 display the density functions for bentonite and montmorillonite under various humidities. As already suggested by results obtained in transmission and by raw data (Figures 4 and 5), bentonite is only slightly oriented while orientation is much more pronounced in montmorillonite with very low particle density for orientation parallel to pellet surface (low angles) and sharp increases for oblique orientation. The fact that compression has only little influence on clay orientation in bentonite was already observed by Pret (Pret, 2003) in the case of MX-80 bentonite. It can be easily explained by the fact that accessory minerals limit clay aggregate deformation during compaction due to the formation of a rigid skeleton (Neaman et al., 2003).

Histograms of Figure 6 reveal an additional feature that was not obvious on the raw data (Figure 5): hydration tends to slightly disorientate the particles. In the case of montmorillonite, it starts being significant for a relative pressure of 0.65 , i.e. when an 
important proportion of clay layers reach the two-layer hydrate. The small preferential orientation observed for dry bentonite vanishes in the same way for hydrated samples.

In order to see the effect of confinement on crystalline swelling, Figure 7 presents together the evolution with relative pressure of the d-spacing determined with either X-ray or neutron diffraction. For low relative pressure up to roughly 0.50 , the two sets of data are superimposed. It must be pointed out that the data obtained for bentonite and purified Namontmorillonite are similar, which confirms that sodium-exchanged layers dominate the swelling behavior of bentonite. For higher relative pressure, the d-spacings obtained by neutron scattering on confined pellets start deviating towards higher values for both bentonite and montmorillonite. This is particularly striking for confined bentonite equilibrated at $98 \%$ relative humidity, that displays a main peak at $18.6 \AA$ whereas the free pellet exhibits a dspacing around $16 \AA$. In order to double-check this result which could appear counterintuitive, a bentonite powder was equilibrated with saturated $\mathrm{CuSO}_{4} \cdot 5 \mathrm{H}_{2} \mathrm{O}$ and examined by X-ray diffraction. The resulting diffractogram is presented in Figure 8. It displays a main peak around $16 \AA$ and a small shoulder at $18.6 \AA$, which confirms that in the conditions used in our experiments, bentonite swells more at high water relative pressure when confined.

A tentative explanation for this result, keeping in mind that in the case of montmorillonite, the sapphire window broke under a water relative pressure of 0.98 , can be found by looking, for a total density of 1.7, at the total volume available in the system (Figure 9). Based on the mineralogical composition of MX-80 bentonite, it seems reasonable to assume a solid density of around 2.7 for both bentonite and montmorillonite. In those conditions, for a density after compaction of 1.7 , the total volume available for water in the system can be estimated at around $0.24 \mathrm{~cm}^{3} \cdot \mathrm{g}^{-1}$. If one reports the water adsorption isotherm of bentonite and montmorillonite, it appears that for a solid density of 1.7 , bentonite can just accommodate the adsorbed water amount for a relative pressure of 0.98 (Figure 9A) whereas in the case of 
montmorillonite there is not enough free space available (Figure 9B). This latter calculation can explain why the sapphire window did not resist when confined montmorillonite was equilibrated at a relative pressure of 0.98 . In the case of bentonite, the effect of confinement is to modify the repartition of water molecules between the interlayer spaces and the interaggregate pores. When the sample is free to swell, at high relative pressure, the porous network is modified (thickness expansion of the pellet) and water tends to adsorb in the pores rather than in the interlayer spaces (Bihannic et al., 1998). This is due to the fact that the formation energy of the three-layer hydrate is certainly rather low for Na-montmorillonite. Indeed, the evolution of immersion enthalpy as a function of water precoverage (Cases et al, 1992; Bérend et al., 1995) displays a pseudo-plateau for relative pressures higher than 0.85 . In the case of the confined sample, the porous network cannot be modified. As a consequence, microscopic swelling of montmorillonite particles occurs at the expense of porosity which decreases in volume with possible orientation changes of clay particles according to the geometry of the pores. At very high relative humidities, the minimization of water pressure resulting from swelling pressure in montmorillonite particles is such that the most favorable sites for water adsorption are located in the interlayer space thus leading to the formation of a well-defined three-layer hydrate. It would be particularly interesting to confirm the tendencies observed in this study by performing simulation experiments able to define with some precision the actual formation enthalpy of the three-layer hydrate and comparing it with the adsorption enthalpy associated with water vapor adsorption in pores of various dimensions.

\section{Conclusion and perspectives.}

Neutron diffraction appears as a particularly useful tool to study the crystalline swelling of clay-based samples in constrained conditions in a wide range of relative humidity. As expected, hydration in constrained conditions does not differ from free conditions for low 
relative humidity. At high water relative pressure and for moderate compaction $(\mathrm{d}=1.7)$, confinement appears to modify the repartition of water molecules between inter-aggregate pores and interlayer spaces favoring adsorption in the interlayer domain thus leading to the early formation of a three-layer hydrate.

Furthermore, differences in behavior of montmorillonite and bentonite at $98 \%$ suggest that the voids present between clay particles at the dry state disappear or decrease strongly when hydration occurs in confined conditions. Changes in the evolution of the porous network of clay pellets with water relative pressure, solid density and confinement should then be studied in detail. Such parameters can also be obtained in situ with the same confinement cells by small angle neutron scattering experiments that are currently under progress.

Acknowledgement: this research was funded by Andra (Agence Nationale de gestion des Déchets Radioactifs); ILL (Institut Laue-Langevin) is acknowledged for providing beamtime and technical assistance in the design of the confinement cells.

\section{References}

Ben Rhaïem, H., Pons, C.H., Tessier, D., 1987. Factors affecting the microstructure of smectites rôle of cation and history of applied stresses. Proc. Int Clay Conf. Denver (1985) L.G. Schultz, H. Van Olphen and F.A. Mumpton eds., The clay minerals society, Bloomington IN, pp. 292-297.

Bihannic, I., 1998. Structure et microtexture du gonflement cristallin de la montmorillonite, Thèse de l'Université d'Orléans, 175p.

Bihannic, I., Tchoubar, D., Lyonnard, S., Besson, G., Thomas, F., 2001. X-ray scattering investigation of swelling clay fabric. 1- the dry state. J. Colloid Interface Sci., 240, 211-218.

Bérend, I., Cases, J.M.., François, M., Uriot, J.-P., Michot, L.J., Masion, A., Thomas, F., 1995. Mechanism of adsorption and desorption of water vapor by homoionic montmorillonite 2: The $\mathrm{Li}^{+}, \mathrm{Na}^{+}, \mathrm{K}^{+}, \mathrm{Rb}^{+}$and $\mathrm{Cs}^{+}$exchanged forms, Clays Clay Miner. 43, 324-336. 
Brunauer, S., Emmett, P.H., Teller, E., 1938. Adsorption of gases in multimolecular layers. J. Am. Chem. Soc. 60 309-319.

Cases, J.M., Bérend, I., Besson, G., François, M., Uriot, J.P., Thomas, F., Poirier J.E., 1992. Mechanism of adsorption and desorption of water vapour by homoionic montmorillonite : I. The sodium exchange form. Langmuir, 8, 2730-2739.

Cases, J.M., Bérend, I., François, M., Uriot, J.-P., Michot, L.J., Thomas, F., 1997. Mechanism of adsorption and desorption of water vapor by homoionic montmorillonite 3: The $\mathrm{Mg}^{2+}, \mathrm{Ca}^{2+}, \mathrm{Sr}^{2+}$ and $\mathrm{Ba}^{2+}$ exchanged forms, Clays Clay Miner. 45, 8-22.

Choi, J.W., Oscarson, D.W., 1996. Diffusive transport through compacted Na- and Cabentonite. J. Contaminant Hydrol., 22, 189-202

Christidis, G.E., Eberl, D.D., 2003. Determination of layer charge characteristics of smectites. Clays Clay Minerals, 45, 8-22.

Drits, V. A, Tchoubar, C., 1990. X-ray diffraction by disordered lamellar structures. Theory and applications to microdivided silicates and carbons. - Springer-Verlag, Berlin, $371 \mathrm{pp}$.

Ferrage, E., Lanson, B., Sakharov, B.A., Drits, V.A., 2005a. Investigation of smectite hydration properties by X-ray diffraction profiles. Part 1. Montmorillonite hydration properties. American Mineralogist, in press.

Ferrage, E., Lanson, B., Malikova, N., Sakharov, B.A., Plançon, A., Drits, V.A., 2005b. New insights on the distribution of interlayer water in bi-hydrated smectite from X-ray Profile modeling of 001 reflections. Chemistry of materials, submitted.

Harkins, W.D., Jura, G., 1944. An absolute method for the determination of the area of a finely divided crystalline solid. J. Am. Chem. Soc. 66, 1366-1375.

Komine, H., Ogata, N., 1994. Experimental study on swelling characteristics of compacted bentonite. Can. Geotech. J. 31, 478-490.

Landais, P., 2004. Clays in natural and engineered barriers for radioactive waste confinement. Applied Clay Sci. 26, 1.

Low, P.F., 1980. The swelling of clay. II. Montmorillonites. Soil Sci. Soc. Am. J., 44, 667676.

Madsen, F.T., 1998. Clay mineralogical investigations related to nuclear waste disposal, Clay Miner. 33, 109-129.

Michot, L.J., Bihannic, I., Pelletier M., Rinnert, E., Robert, J.L., 2005. Hydration and swelling of synthetic Na-saponites: influence of layer charge. Amer. Min., 90, 166-172. 
Mooney, R.W., Keenan, A.G., Wood, L.A., 1952. Adsorption of water vapor by montmorillonite. II- Effect of exchangeable ions and lattice swelling as measured by X-ray diffraction. J. Am. Chem. Soc. 74, 1371-1374.

Morvan, M., Espinat, D., Lambard, J., Zemb, Th,1994. Ultrasmall- and small-angle X-ray scattering of smectite clay suspensions. Colloids and Surfaces A: Physicochemical and engineering aspects 82, 193-203.

Nakaoka, K., Yamamoto, S., Hasegawa, H., Kawaruma, H., Kitayama, K., Saito, N., Ichikawa, Y., Kawaruma, K., Nakano, M., 2004. Long-term consolidation mechanisms based on micro-macro behavior and in situ XRD measurement of basal spacing of clay minerals. Applied Clay Sci. 26, 521-533.

Neaman, A., Pelletier, M., Villiéras, F., 2003. Effects of thermal treatment, exchangeable cation and compression on textural properties of MX-80 bentonite. Applied Clay Sci. 22, 153-168.

Newman, A.C.D., 1987. The Interaction of Water with Clay Mineral Surfaces., in Chemistry of Clays and Clay Minerals. A.C.D. ed. Newman, Mineralogical Society, London, pp 237-285.

Norrish, K., Quirk, J.P., 1954. Crystalline swelling of montmorillonite. Nature, 173, 225-256.

Ormerod, E.D., Newman, A.C.D., 1983. Water sorption on Ca-saturated clays: II. Internal and external surfaces of montmorillonite. Clay Miner., 18, 289-299.

Poirier, J.E., François, M., Cases, J.M., Rouquero, J., 1987. Study of Water Adsorption on Na-Montmorillonite : New Data Owing to the Use of a Continuous Procedure. In Fundamentals of Adsorption. Liapis, A.I ed., A.I.C.H.E. pp. 473-480.

Prêt, D., 2003. Nouvelles méthodes quantitatives de cartographie de la minéralogie et de la porosité dans les matériaux argileux: application aux bentonites compactées des barrières ouvragées. Thèse de l'Université de Poitiers, Poitiers, France, 259 p.

Pusch, R., Hömark, H., Karnland, O., 1990. Microstructural impact on the conductivity of smectite buffer clays. Sci. Géol., Mém, Strasbourg, 87, 127-137.

Pusch, R., Schomburg, J., 1999. Impact of microstructure on the hydraulic conductivity of undisturbed and artificially prepared smectitic clay. Engineering Geology 54, 167172.

Pusch, R., Yong, R., 2003. Water saturation and retention of hydrophilic clay buffermicrostructural aspects. Applied Clay Sci. 23, 61-68.

Sauzéat, E., Guillaume, D., Neaman, A., Dubessy, J., François, M., Pfeiffert, C., Pelletier, M., Ruck, R., Barrès, O., Yvon, J., Villiéras, F., Cathelineau, M., 2001. Caractérisation 
fine de l'argile brute MX-80 : Caractérisation minéralogique, cristallochimique et texturale de l'argile MX-80. ANDRA C RP 1ENG 01-001, 94 p.

Skipper, N.T., Williams, G.D., de Siqueira, A.V.C., Lobban, C., Soper ,A.K., 2000. Time-offlight neutron diffraction studies of clay-fluid interactions under basin conditions. Clay Miner. 35, 283-290.

Sposito, G., Prost, R., 1983. Structure of water adsorbed on smectites. Chemical Reviews, 82, 553-573.

Stucki, J.W., Low, P.F., Roth, C.B, 1984, Effects of oxidation state of octahedral iron on clay swelling. Clays Clay Miner. 32, 357-362.

Van Olphen, H., 1977. An introduction to clay colloid chemistry. $2^{\text {nd }}$ ed., Wiley, New York. 


\section{Figure caption}

Figure 1: photographs of confinement cells

Figure 2: water vapor adsorption isotherms on bentonite and Na-montmorillonite

Figure 3: XRD basal spacings measured on bentonite pellet hydrated in free condition as a function of relative humidity.

Figure 4: In situ neutron diffraction patterns on a) bentonite and b) Na-montmorillonite compacted samples as a function of relative humidity.

Figure 5: Relative integrated intensities of 001 peak of clay in a) bentonite and b) Namontmorillonite as a function of relative humidity and transmission angle.

Figure 6: orientation densities of clay in a) bentonite and b) Na-smectite as a function of relative humidity.

Figure 7: comparison of X-ray and neutron diffraction basal spacings

Figure 8: X-ray diffraction on bentonite pellet equilibrated in free condition at $98 \% \mathrm{RH}$ with a solution saturated by $\mathrm{CuSO}_{4} .5 \mathrm{H}_{2} \mathrm{O}$

Figure 9: Comparison of equilibrium conditions with water adsorption capacity derived from total pore volume in a) bentonite and b) Na-montmorillonite. 


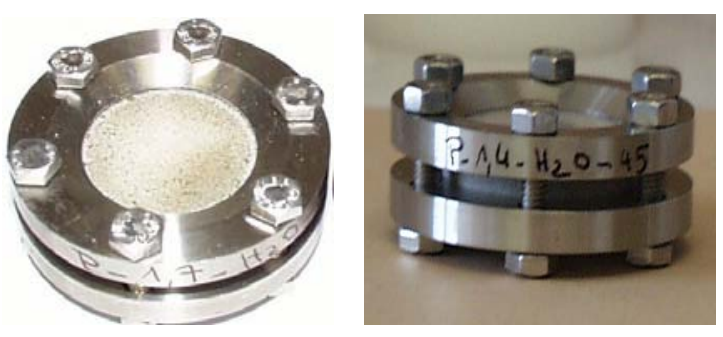

Figure 1: photographs of confinement cells 


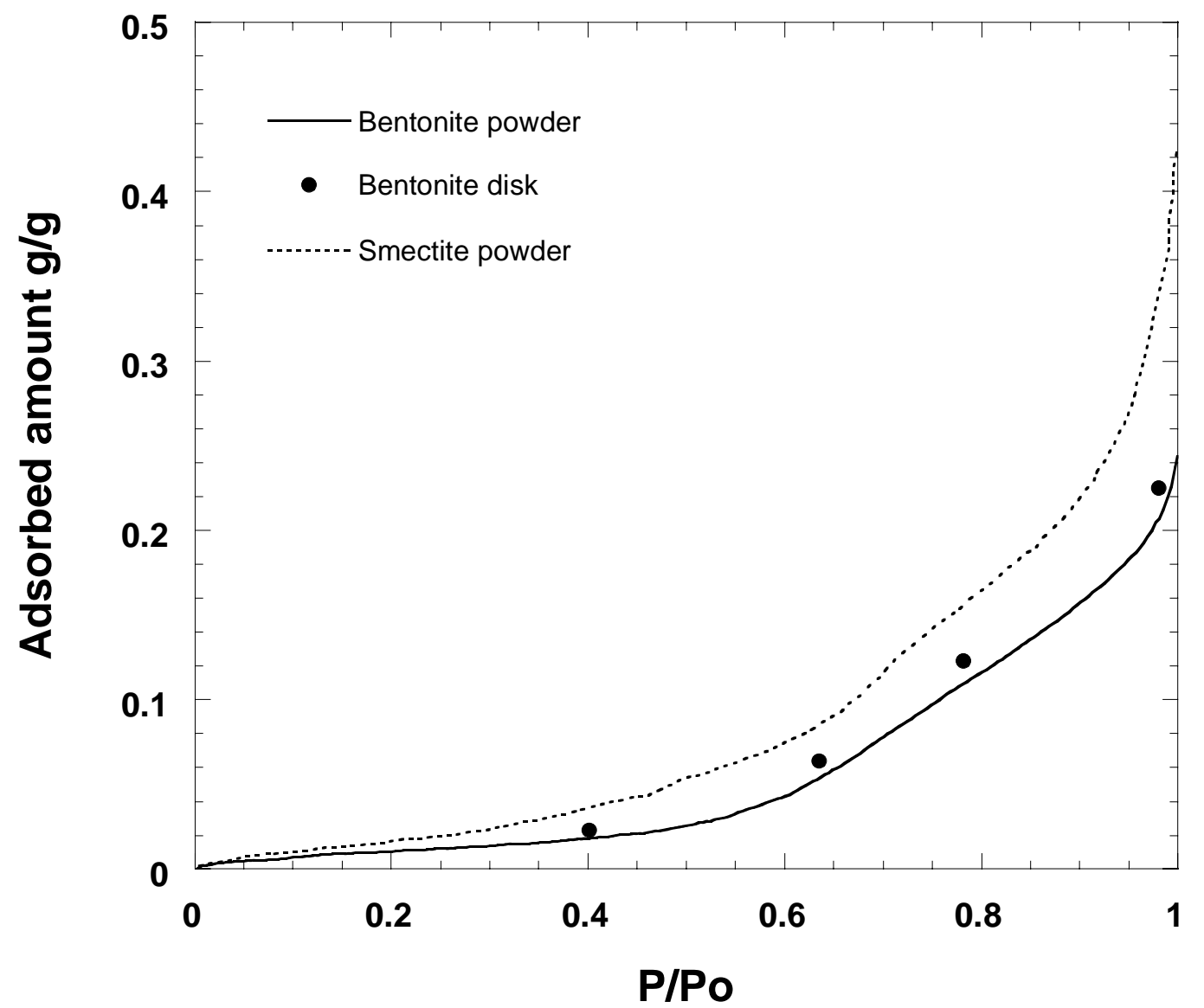

Figure 2: water vapor adsorption isotherms on bentonite and Na-montmorillonite 


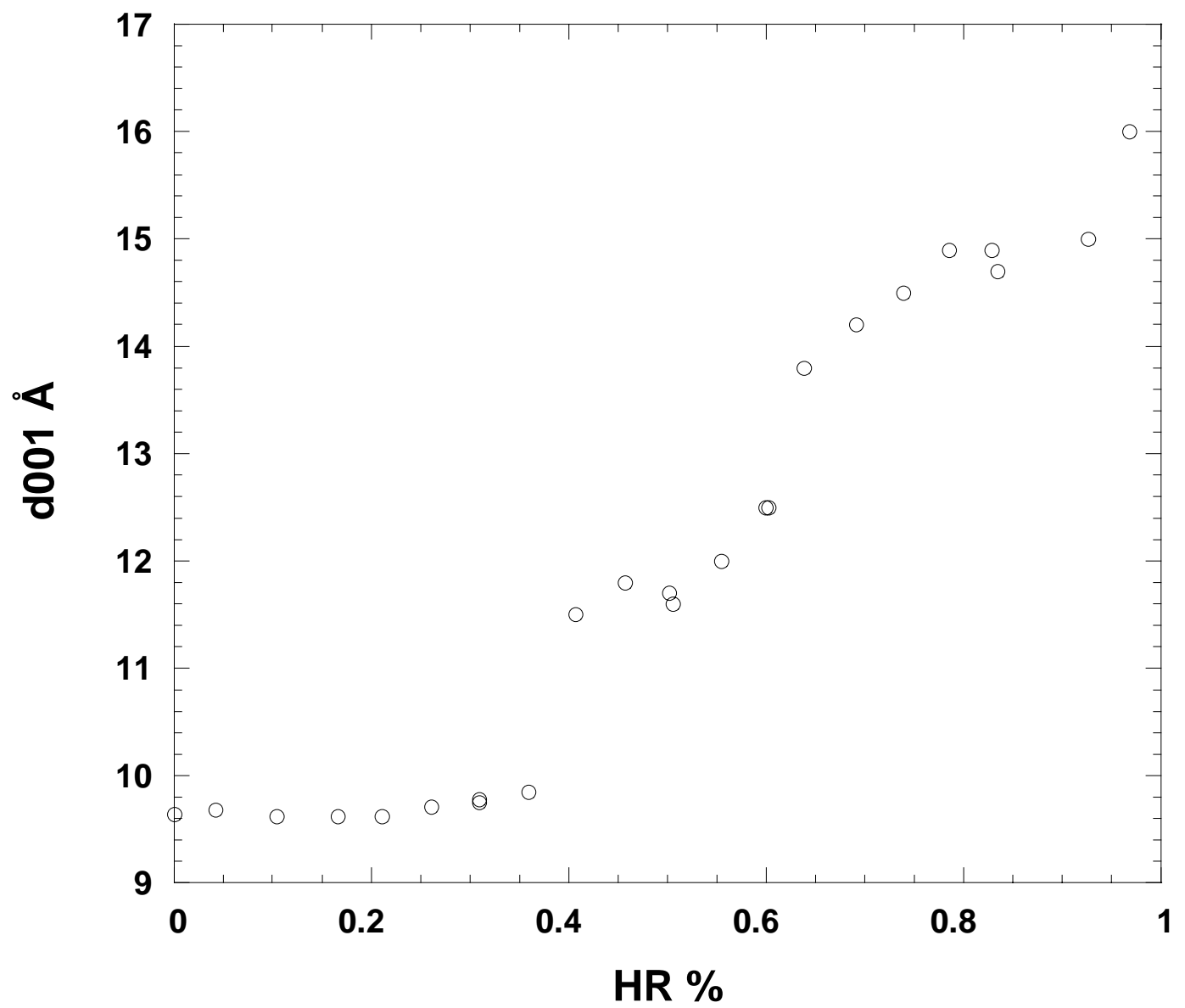

Figure 3: XRD basal spacings measured on free bentonite pellet as a function of relative humidity. 

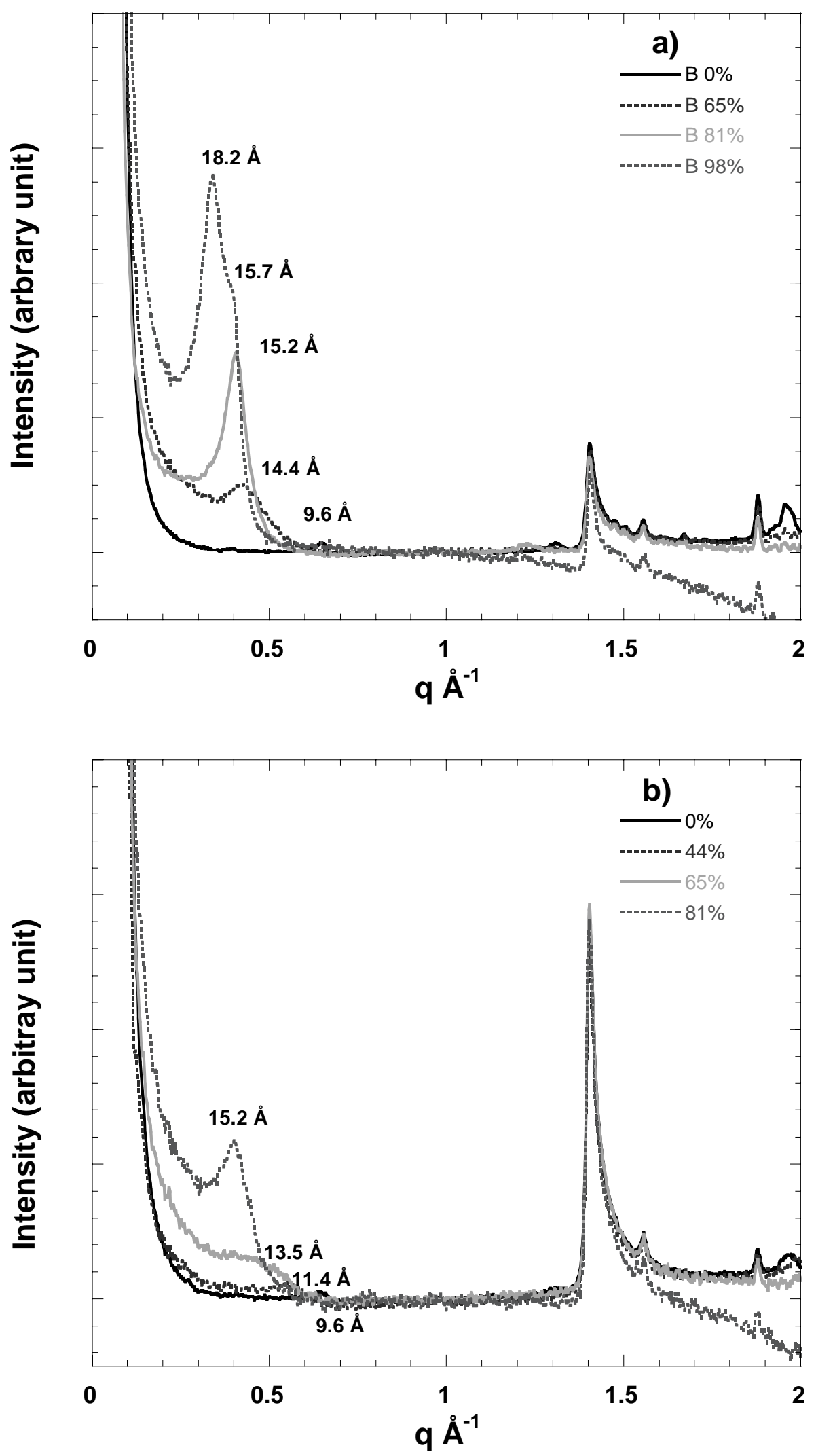

Figure 4: In situ neutron diffraction patterns on a) bentonite and b) Na-montmorillonite compacted samples as a function of relative humidity. 

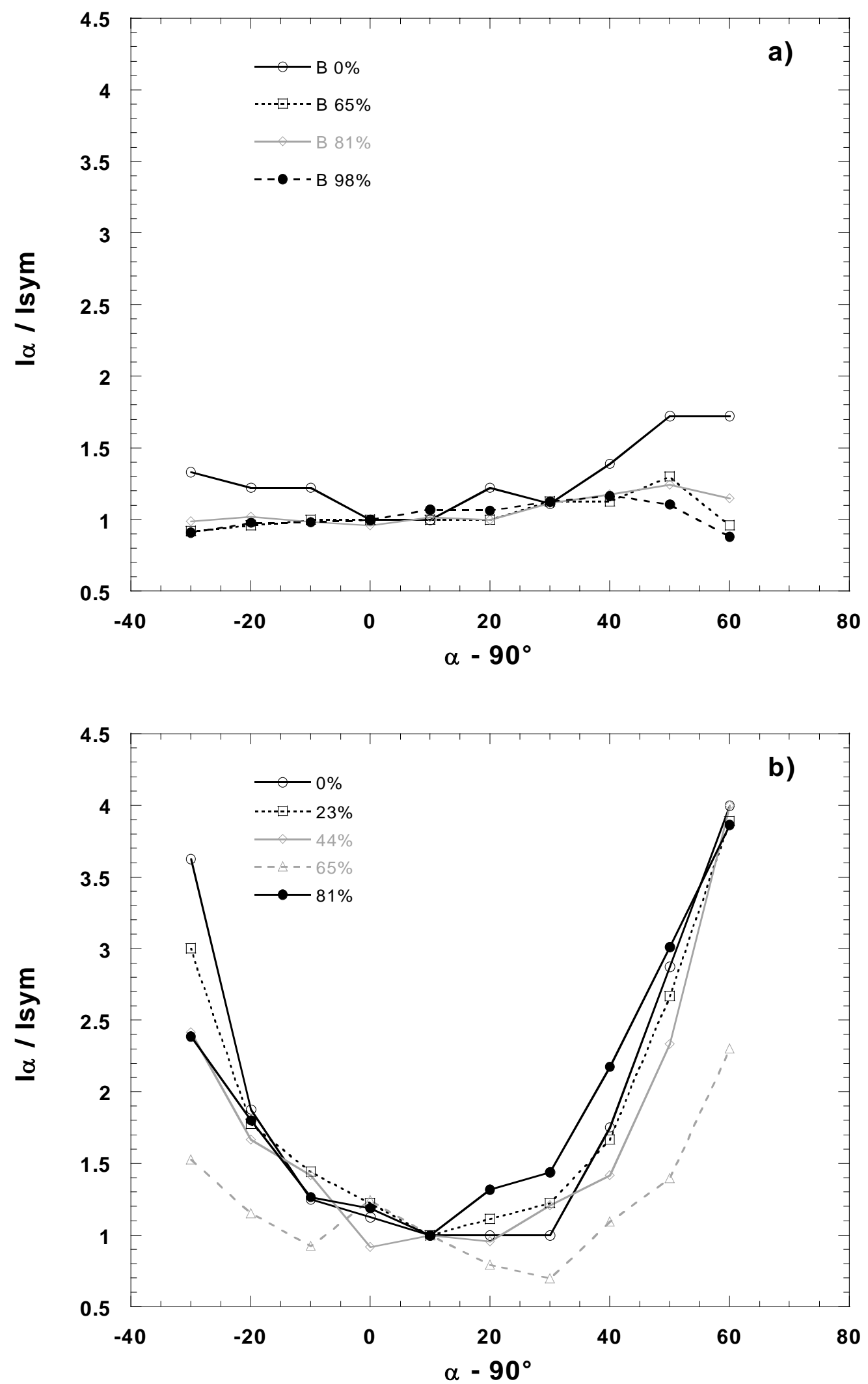

Figure 5: Relative integrated intensities of 001 peak of clay in a) bentonite and b) Namontmorillonite as a function of relative humidity and transmission angle. 

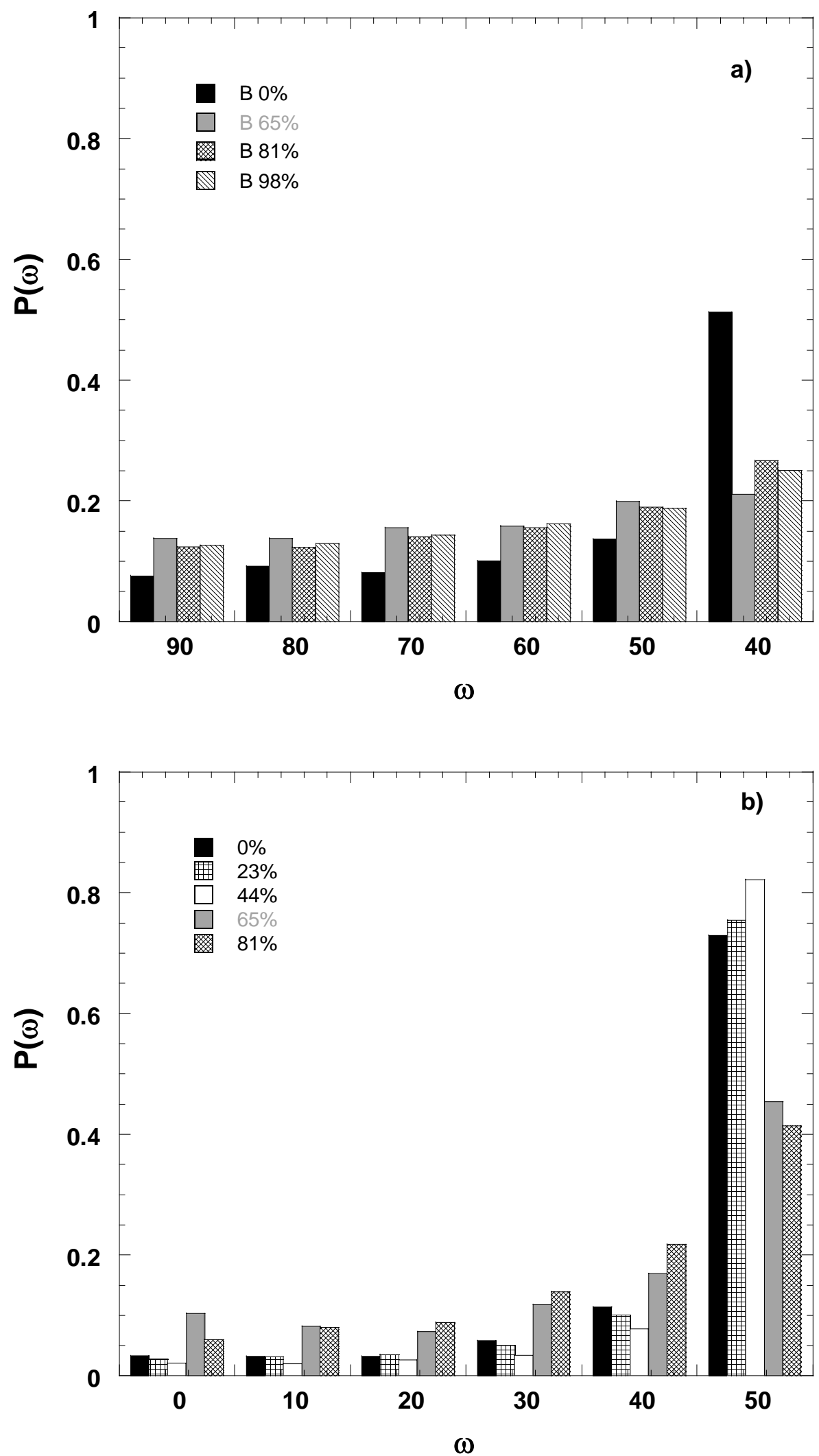

Figure 6: orientation densities of clay in a) bentonite and b) Na-smectite as a function of relative humidity. 


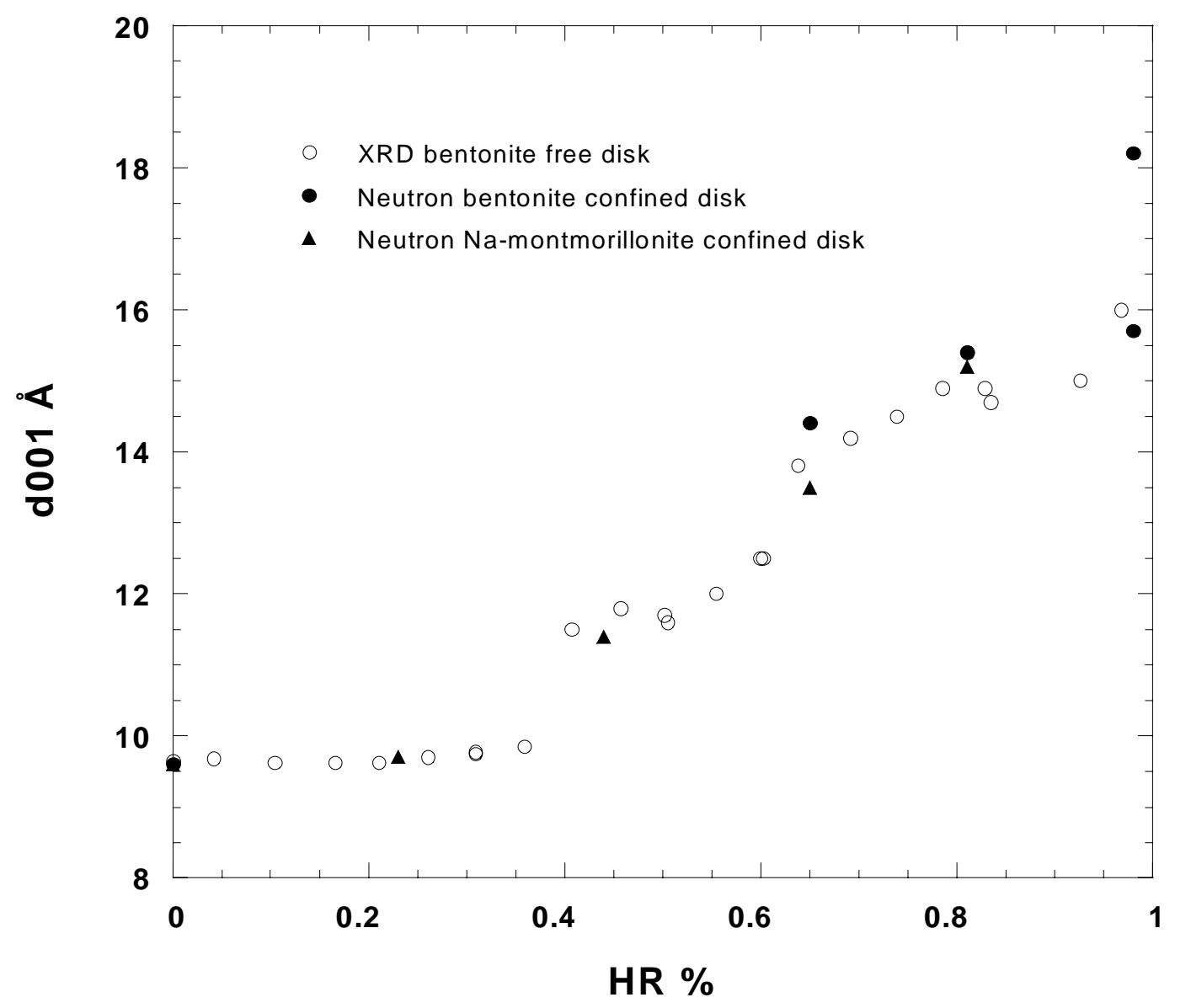

Figure 7: comparison of X-ray and neutron diffraction basal spacings 


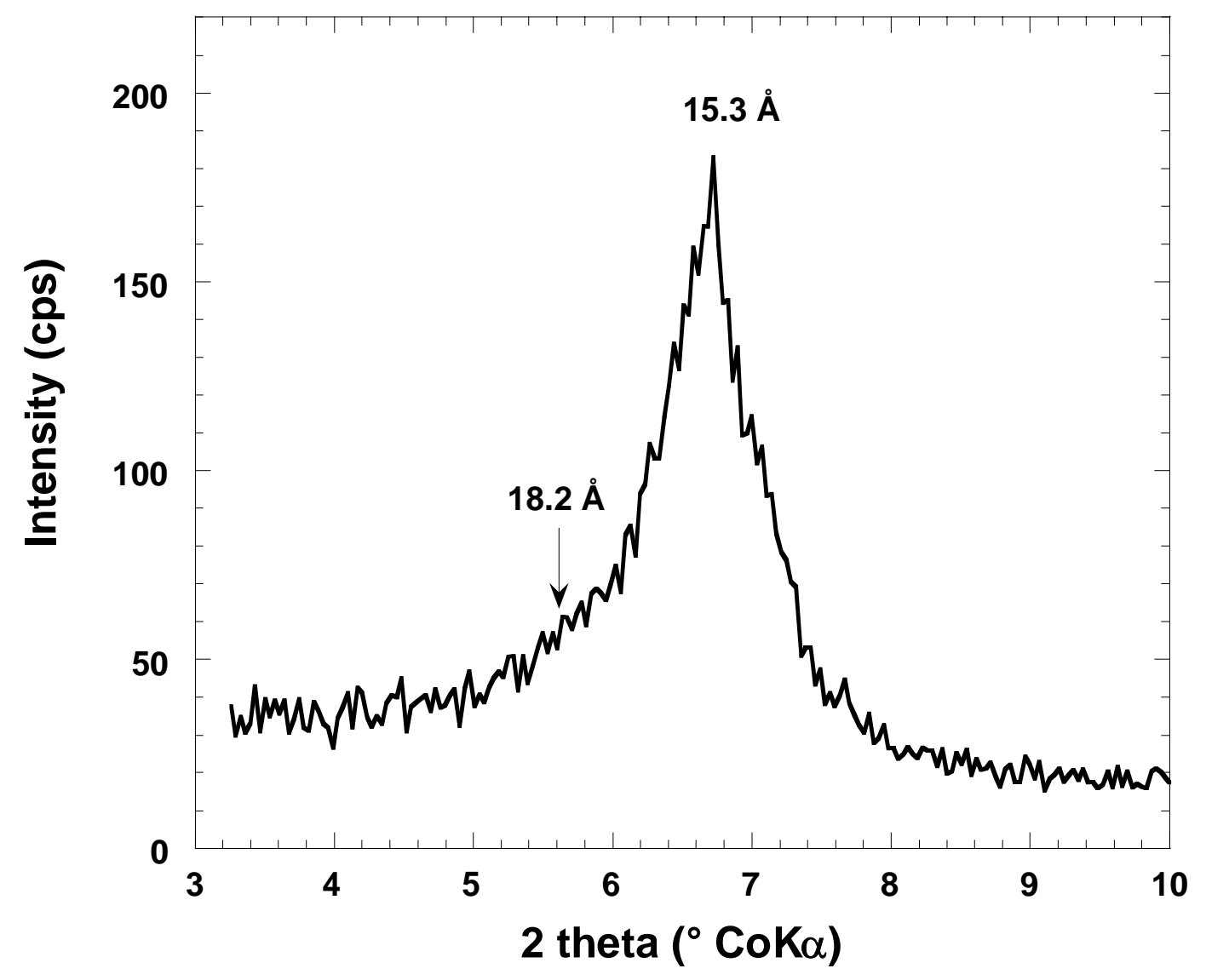

Figure 8: X-ray diffraction on bentonite free disk equilibrated at $98 \% \mathrm{RH}$ with a solution saturated by CuSO4.5H2O 

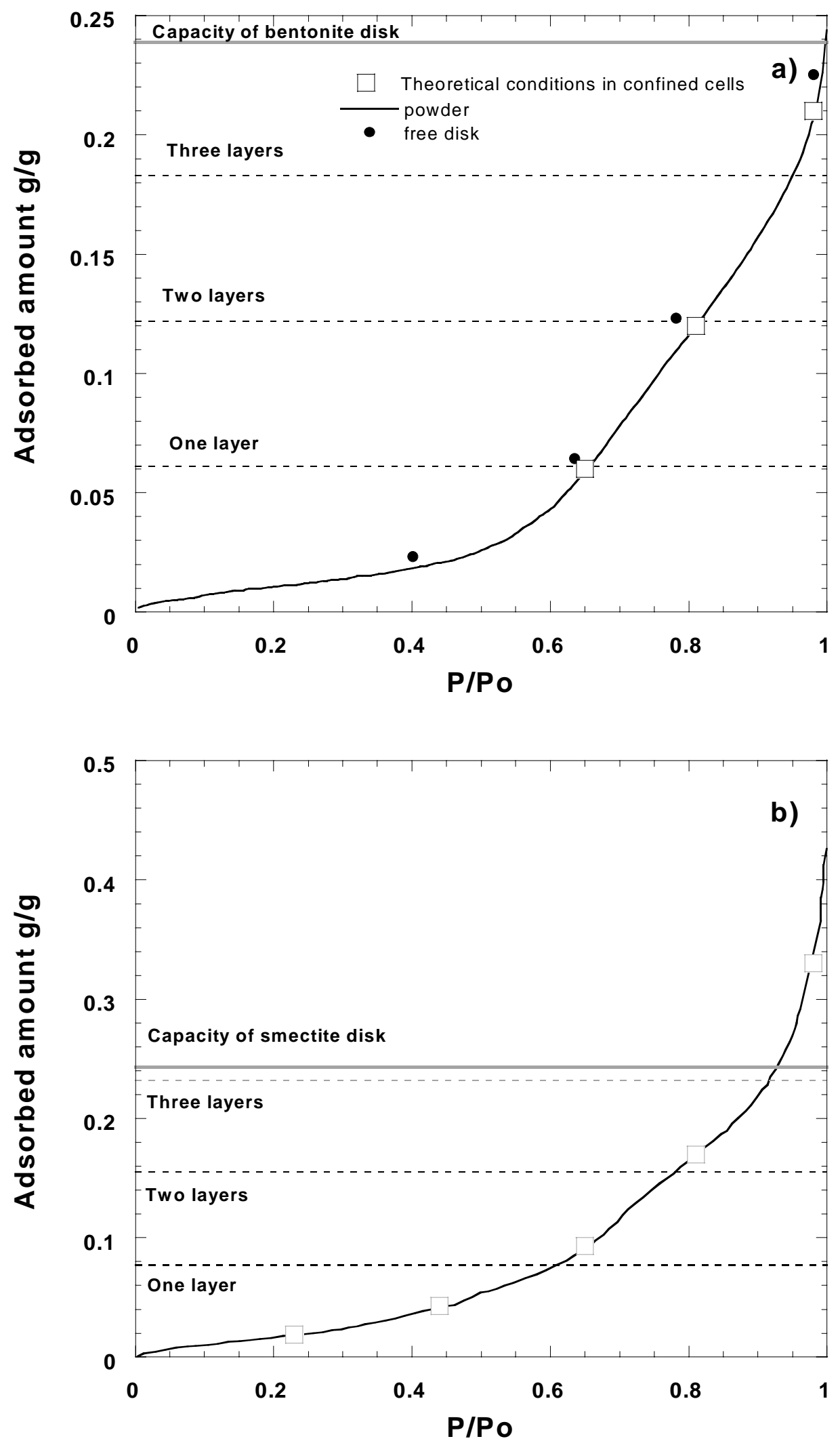

Figure 9: Comparison of equilibrium conditions with water adsorption capacity derived from total pore volume in a) bentonite and b) Na-montmorillonite. 